\title{
Use of Raman Spectroscopy in Characterizing Soft X-ray Multilayers: Tools in Understanding Structure and Interfaces
}

\author{
Ming Cai \\ mingcai2000@yahoo.com
}

Qi Wang

David D. Allred

allred@byu.edu

Larry V. Knight

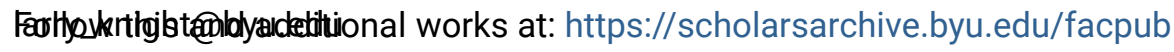

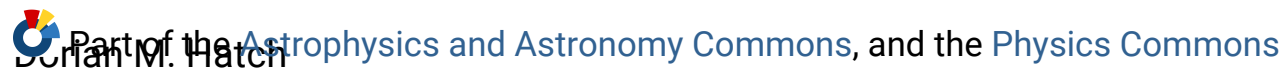

\section{Original Publication Citation}

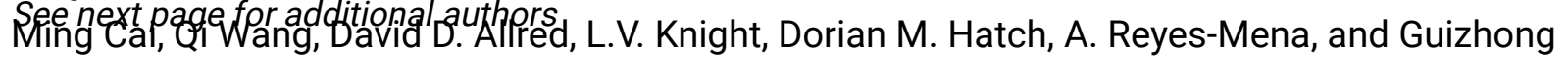
Zhang, "The Use of Raman Spectroscopy in Characterizing Soft X Ray Multilayers: Tools in Understanding Structure and Interfaces," Optical Materials for High Power Lasers, Proceedings of SPIE, 1848, 24th Boulder Damage Symposium, Boulder, CO, October 28 3, 1992. http://spiedigitallibrary.org/proceedings/resource/2/psisdg/1848/1/521_1?isAuthorized=no http://dx.doi.org/1.1117/12.147396

\section{BYU ScholarsArchive Citation}

Cai, Ming; Wang, Qi; Allred, David D.; Knight, Larry V.; Hatch, Dorian M.; Reyes-Mena, A.; and Zhang, Guizhong, "Use of Raman Spectroscopy in Characterizing Soft X-ray Multilayers: Tools in Understanding Structure and Interfaces" (1992). Faculty Publications. 1183.

https://scholarsarchive.byu.edu/facpub/1183

This Peer-Reviewed Article is brought to you for free and open access by BYU ScholarsArchive. It has been accepted for inclusion in Faculty Publications by an authorized administrator of BYU ScholarsArchive. For more information, please contact ellen_amatangelo@byu.edu. 
Authors

Ming Cai, Qi Wang, David D. Allred, Larry V. Knight, Dorian M. Hatch, A. Reyes-Mena, and Guizhong Zhang

This peer-reviewed article is available at BYU ScholarsArchive: https://scholarsarchive.byu.edu/facpub/1183 
Use of Raman spectroscopy in characterizing soft $x$-ray multilayers:

Tools in understanding structure and interfaces

\author{
Ming Cai, Qi Wang*, David D. Allred, Larry V. Knight, Dorian M. Hatch, \\ A. Reyes-Mena*t, and Guizhong Zhang* \\ Department of Physics and Astronomy, Brigham Young University, Provo, Utah 84602. \\ *Also at MOXTEK, Inc., Provo, Utah 84604; \\ †Also at Departamento de Fisica, Cinvestav, IPN, Mexico, 07000, DF; \\ $\ddagger$ Also at Tianjin University, P. R. China.
}

\begin{abstract}
Our group is studying the structure and interfaces of soft $x$-ray multilayers by various techniques including $x$-ray diffraction and Raman spectroscopy. Raman spectroscopy is particularly useful since it is sensitive to the identity of individual bonds and thus can potentially characterize the abruptness of interfaces in multilayers. Blocking interfacial mixing is very important in achieving and maintaining high reflectivity. We report our studies of the as-deposited and postannealed structure of $\mathrm{Mo} / \mathrm{Si}$ and W/C multilayers. The $\mathrm{Mo} / \mathrm{Si}$ system is probatly the most widely studied multilayer currently because of its potential applications for soft $\mathrm{x}$-ray projection lithography for the range of 13 to $15 \mathrm{~nm}$. A high normal-incidence, peak reflectance is mandatory for imaging applications that involve many reflections. The reported theoretical and achieved reflectances of the $\mathrm{Mo} / \mathrm{Si}$ system are $80 \%$ and $65 \%$ resprectively. This loss of $15 \%$ can bring about a six-fold loss in system throughput in the eight-reflection system contemplated. The interfaces in the $\mathrm{Mo} / \mathrm{Si}$ system are thought to play a significant role in the degrading reflectance so characterization techniques which have interfacial sensitivity are particularly important. The $\mathrm{M} / \mathrm{Si}$ multilayer system is susceptible to Raman characterization since hoth the a-Si spacer layer and the $\mathrm{MoSi}_{2}$ compo:nd which forms at the interface have Raman active modes. In this paper we report the tirst Raman studie;, to be west of our knowledge, of the a-Si layers and their crystallization and the crystallization of the $\mathrm{Mo} / \mathrm{Si}$ inter face of the multilayer brought about by a one-hour $1000^{\circ} \mathrm{C}$ anneal. These changes are apparent in the Raman spectra before they can be unambiguously detected by $\mathrm{x}$-ray diffraction.
\end{abstract}

\title{
1. INTRODUCTION
}

Understanding the formation of refractory metal silicides at the interfaces of thin films is an extremaly interesting basic science and an important technological problem. Technologically, the formation of silicide is important in very large-scale integration (VLSI) where silicides are being used 3 s interconnect films $\mathrm{s}^{1.2}$ and in producing better soft $x$-ray multilayers, since their presence at interfaces in res! Mo/Si multilayers keeps the piuk reflectance from achieving the theoretical maximum of $80 \%$ which is predicted for me itilayers containing atomic: tly abrupt and smooth interfaces.

Besides their applications in $x$-ray imaging technology and microelectronics, multilavers have also proven to be a convenient way of studying the nanoscale prop urties of materials -- for example, the crystallization and interdiffusion of matter on atomic scales. ${ }^{3,4}$

In the current $x$-ray imaging revolution periodic bilayer multilayers have played an important role. ${ }^{5}$ These multilayer mirrors, which are used to reflect light with the wavelengths in soft $x$ rays, typically consist of periodic multiple bilayers, ench bilayer composed of a low- $Z$ and high-Z layer. The reflectance is achieved by tie interference occurring at the sharp interfaces between these layers. Generally speaking, the sharper the interfaces, the higher the reflectance which can be obtained. Any modification of the interfaces will directly impact the optical performance of the multilayer. Techniques which can detect and quantify the intermixing at interfaces are extre:nely important for preparing the superior multilayers required for soft $x$-ray projection lithography, since a $10 \%$ gain in the reflectance in each of the mirrors of the eight-mirror systems contemiplated for lithography can triple the light through the camera. 
Small angle $x$-ray diffraction (SAXRD) and direct imaging by scanning transmission electron microscopy (STEM) have been successful in characterizing interfaces of soft $x$-ray multilayers but can give artificially wide estimates of interfaces. Raman spectroscopy has also been shown to be a useful technique for characterizing multilayers of amorphous semiconductors, such as $\mathrm{Si} / \mathrm{Ge},{ }^{6}$ and multilayers of metal/carbon, such as W/C multilayers ${ }^{7}$ because it can directly "count" interfacial bonds in some cases. Observing the interfaces of the multilayers is especially important, but under some circumstances this is very difficult and may require special care. This is because of the small volume of material within the interfaces and the interface bonds may have a low Raman cross section.

So far, $\mathrm{Mo} / \mathrm{Si}$ is the most efficient multilayer mirror for the soft $\mathrm{x}$-ray range of $13-30 \mathrm{~nm}^{8.11}$ A large number of groups are studying these multilayers and their applications because of the high theoretical and achieved peak reflectances of $80 \%$ and $65 \%$, respectively, over the 12.5 to $16 \mathrm{~nm}$ range. This is the preferred range for projection soft $x$-ray lithography. We are the first group to apply a Raman spectroscopic technique to characterize soft $\mathrm{x}$-ray $\mathrm{Mo} / \mathrm{Si}$ multilayers. ${ }^{12}$ We have observed the presence of a-Si in as-deposited multilayers, its disappearance and the formation of crystalline $\mathrm{MoSi}_{2}$ in annealed multilayers. The Raman spectroscopy study of commercial $\mathrm{MoSi}_{2}$ powder has also been carried out to help identify the $\mathrm{MoSi}_{2}$ peaks. Both large angle $\mathrm{x}$-ray diffraction (LAXRD) and SAXRD measurements have been performed to aid to understand Raman results. Scanning electron microscopy (SEM) measurements provide direct picture of the surface topology evolution during annealing.

\section{EXPERIMENTAL}

The multilayer interfacial regions consist of a mixture of molybdenum and silicon, so that the study of molybdenum silicide is required for Raman studies of $\mathrm{Mo} / \mathrm{Si}$ multilayers and we began with a study of molybdenum disilicide $\left(\mathrm{MoSi}_{2}\right)$ powder. For this reason, this study of multilayers has applications beyond the study of soft $\mathrm{x}$-ray reflectors since silicides are expected to be important materials for high-speed electronics and very large-scale integration (VLSI). This is because many refractory metal silicides have been found to have very high thermal and chemical stability and high electrical conductivity. Because of these applicutions, silicides have received substantial attention, and a large number of studies have been carried out on them. ${ }^{1.2}$ Many silicides such as WSi., PtSi, and $\mathrm{TiSi}_{2}$ have been extensively studied by Raman spectroscopy, ${ }^{13-19}$ but there has only been one published report on $\mathrm{MoSi}_{2} \cdot{ }^{19}$

The molybdenum disilicide powder was purchased from Aldrich Chemical Company, Inc. The powder's average particle size is about $1 \mu \mathrm{m}$ and its manufacturer quotes the purity as $99+\%$. The bulk material was obtained to provide a standard with which to compare the thin film material.

In addition to studying the as-received $\mathrm{MoSi}_{2}$ powder and the as-deposited thin film samples, isoth powder and films were subjected to vacuum arrealing, to air annealing, and the powder to $\mathrm{KOH}$ etching. This was done to aid understanding of the observed features in Raman and $x$-ray diffraction spectra. The vacuum annealing consisted of sealing the sample in an evacuated quartz tube or glass ampoule. For the sample annealed in air, the ampoule was not sealed. The furnace was controlled to $1000^{\circ} \mathrm{C}$ and the sample was placed directly in ihe hot oven at the beginning of the annealing time and air quenched by withdrawing the ampoule directly from the furnace at the end of the annealing time. As an alternative to annealing and to etch out the unreacted materials and impurities, some of the powder was mixed with $\mathrm{KOH}$ solution $(10 \mathrm{M} / \mathrm{KOH})$ filtered and dried in air in a $110^{\circ} \mathrm{C}$ oven. This etching process was observed to remove most of the residue unreacted silicon.

The multilayer samples were made by dc magnetron sputtering for a fixed target system. Layering was achieved by rotating the substrate in the system at a fixed rate over the sources. The $\mathrm{Mu} / \mathrm{Si}$ multilayers were prepared for soft $x$-ray mirror (plasma diagnostic) applications and were shown to have excellent soft $x$-ray reflectance. The sputtering targets were molybdenum metal and p-type silicon. The sample substrates were ultrasmooth crystalline silicon wafers of [100] orientation. The period $\Lambda$ or $\mathrm{d}$-spacing was measured to be $8.4 \mathrm{~nm}$, as deposited, with a nominal $\gamma=\mathrm{d}_{\mathrm{Mo}_{0}} /\left(\mathrm{d}_{\mathrm{si}_{\mathrm{i}}}+\mathrm{d}_{\mathrm{M}_{0}}\right)$ of 0.40 . There were 30 pairs. The total multilayer thickness is thus about $250 \mathrm{~nm}$. The top layer is amorphous silicon and is twice as thick as other layers to retard oxidation. The multilayer samples were also sealed in vacuum and annealed at temperatures ranging fi i $\mathrm{n} 300$ to $1000^{\circ} \mathrm{C}$. 
From now on we refer it as thick multilayer sample.

Another group of $\mathrm{Mo} / \mathrm{Si}$ multilayer sample were prepared to be very thin on purpose to magnify the interface effects. We will call them thin sample from now on to distinguish from the nornal ones described above. The sample substrates were ultrasmooth crystalline silicon wafers of [111] orientation. To use wafer with [111] orientation, we can separate the weak silicides' $x$-ray diffraction signals from the strong substrate signals which are around $30^{\circ}$. The period $\Lambda$ was measured to be $2.0 \mathrm{~nm}$, as deposited, with a nominal $\gamma$ of 0.46 . There were 60 pairs. The top is still the silicon protection layer. These samples were also sealed in vacuum and annealed at temperatures of $300,600,900$, and $1000^{\circ} \mathrm{C}$.

The Raman spectra were recorded on a SPEX 1877 Triplemate spectrometer. The spectrometer consists of a modified Czerny-Turner zero-dispersion double spectrometer as a filter stage and a modified Czerny-Turner spectrograph. The dispersion element used in the spectrograph stage is a 1800 grooves $/ \mathrm{mm}$ holographic grating with $0.92 \mathrm{~nm} / \mathrm{mm}$ dispersion. The spectral bandpass selected was $\sim 18 \mathrm{~cm}^{-1}$. The $514.5 \mathrm{~nm}$ line $(\sim 400 \mathrm{Mw})$ of an argon ion laser (LEXEL 96) was used as the excitation source in most studies. The other laser lines were used on occasion to confirm peak identification. A 1200 grooves $/ \mathrm{mm}$ ruled grating with a small aperture placed outside of the laser cavity was used as a presample monochromator to eliminate the laser plasma lines. The laser heam vas brought to line focus $(1 \times 10 \mathrm{~mm})$ on the sample's surface using a cylindrical lens to match the entrance slit of the triplematc inonochromator; the scattered signals were analyzed by the spectrometer and detected by a photomultiplier (EMI 7981B). Then photon-counting electronics were used to cenvert the light signal into the electrical signal. $\wedge$ 386SX PC was used to control the spectral scanning and data sccptisition through a digital-analog interface hox (TransEra-MDAS-7000).

Both LAXRD and SAXRD measurements were performed before and after a nealing on a SCINTAG DMS2000 powder diffractometer using a $\mathrm{CuK} \alpha$ source $(\lambda=0.154 \mathrm{~nm})$ with power of $35 .: \mathrm{V}-25 \mathrm{~mA}$. SAXRD provides an accurate measurement of the average bilayer spacing of a multilayer mirror. ${ }^{26} \mathrm{~A}$ gen $\mathrm{mal}$ rule is that a large number of orders is indicative of sharp boundaries between the layers.

\section{RESULTS AND DISCUSSION}

The Raman spectra of the commercial molybdenum disilicide powder samples are shown in Figure 1 . The raw powder (as-received) spectrum (see (a)) possesses four peaks: two small broad peaks located at 323 and 438 $\mathrm{cm}^{-1}$ (the higher frequency one is stronger), one fairly sharp peak located at $520 \mathrm{~cm}^{-1}$, and one small peak located at $822 \mathrm{~cm}^{-1}$. We conclude that the sharp peak at $520 \mathrm{~cm}^{-1}$ arises from the unreacte:? polycrystalline siiticin in the powder. This is suggested by its position and was confirmed by two ohservations: first, the fact that the $520 \mathrm{~cm}^{-1}$ peak is lower after vacuum annealing at $1000^{\circ} \mathrm{C}$ (see (b)) and, second, the fact that it is entirely absent after etching in $\mathrm{KOH}$ (see (c)). Strong alkali will etch crystalline silicon but will not etch $\mathrm{MoSi}_{2}$. Other investigators have also reported the presence of unreacted silicon in as-received silicide powders. ${ }^{13.16}$ We conclude that the high-frequency peak is due to $\mathrm{MoO}_{3}$ impurity. This was suspected because of the position of the line and was confirmed by annealing in air (see (d)), as will be discussed below. The two low-frequency peaks are due to MoSi. Doland and Nemanich ${ }^{\text {x }}$ recently reported the position of $\mathrm{MoSi}_{2}$ prepared by annealing Mo on Si wafers as being 325 and 440 $\mathrm{cm}^{-1}$, which are close to our measurements of 323 and $438 \mathrm{~cm}^{-1}$. These peaks are also close to those of $\mathrm{Wsi} i_{2}$ at 331 and $451 \mathrm{~cm}^{-1}{ }^{13}$, which has been studied more extensively. ${ }^{13.16}$ Both $\mathrm{MoSi}_{2}$ and $\mathrm{Wsi}_{2}$ have tetragonal structure with space group $14 / \mathrm{mmm}\left(D_{s h}{ }^{17}\right)$, with the Mo atoms at 2(a) Wyckoff positions and the $\mathrm{Si}$ atoms at $4(\mathrm{c})$. The vihrational mode analysis indicates two active Raman mode, $\Gamma_{1}{ }^{+}\left(A_{1_{6}}\right)$ and $\Gamma_{5}{ }^{+}\left(E_{6}\right)$.

After the powder sample was annealed in vacuum at $1000^{\circ} \mathrm{C}$ for one hour, we saw that the two $\mathrm{MoSi}_{2}$ peaks become sharpur and stronger (see (b)). This can be interpreted as meaning that during the annealing process the original small grains of crystalline $\mathrm{MoSi}_{2}$ grew into larger grains which possess a larger Raman cross siction. Analogous behavior, grain growth with concurrent sharpening and growth of the Raman signal, has been sren in the annealing of amorphous and microcrystalline Si. Note that even after annealing the high-frequency peak is still observable thougin smaller. We interpret this decrease in the silienn peak intensity as the partial reaction of some 
of unreacted silicon during annealing.

To test the hypothesis that the $822 \mathrm{~cm}^{-1}$ peak is due to $\mathrm{MoO}_{3}$ we annealed the same sample again in air at $500{ }^{\circ} \mathrm{C}$ for one hour. The peak became more intense (see (d)). Note that in concert with the intensification many other weak peaks also appear. Their positions are 996, 665, 438, 374, 329, 286, 245, 218, 199, 159, and $129 \mathrm{~cm}^{-1}$. Because the purpose of this experiment was only to verify that the peak at $822 \mathrm{~cm}^{-1}$ is from $\mathrm{MoO}_{3}$, the resoletion was not optimized. This led to the undistinguishable peaks at 374 and $329 \mathrm{~cm}^{-1}$. Jeziorowski reported peaks at .880 , 367,337 , and $292 \mathrm{~cm}^{-1} .{ }^{21} \mathrm{He}$ also reported another peak at $117 \mathrm{~cm}^{-1}$ which we identify as an $\mathrm{Ar}^{+}$laser plasma ine. We have seen this line regardless of the sample we used. The aperture of the plasma-line eliminator is not sufficiently narrow to completely eliminate plasma lines near the elastically scattered laser light. Excluding this 117 $\mathrm{cm}^{-1}$ line and the $\mathrm{MoSi}_{2}$ signal, curve (d) represents a perfect Raman spectrum of $\mathrm{MoO}_{3}, 1,22,3$ The $338 \mathrm{~cm}^{-1}$ peak has been covered by the stronger $\mathrm{MoO}_{3}$ signal. In traces (a) and (b) the oxide impurity was ton small to produce a large Raman signal, and only the strongest peak of the oxide was observed. In (b), because the powder was annealed in vacuum, there is no way for oxide to be removed, so the oxide's signal remains.

Raman spectra from Mo/Si thick multilayers are shown in Figure 2. The spectrum of the ss-deposited multilayer sample only gives a broad bump located approximately at $480 \mathrm{~cm}^{-1}$ (see Figure 2 (a)). We attribute this feature to amorphous silicon. ${ }^{24}$ The silicon layers of $\mathrm{Mo} / \mathrm{Si}$ multilayers have previously been reported to he amorphous on the basis of transmission electron microscopy. ${ }^{25}$ Curve (a) provides direct evidence that these layers are amorphous and, furthermore, indicates that the amorphous silicon is highly defective since the peak is broad and weak. The metal Mo belongs to space group $\operatorname{Im} 3 \mathrm{~m}\left(\mathrm{O}_{\mathrm{h}}{ }^{9}\right)$ and the Mo atoms are at Wyckoff 2(a) positions. This structure does not allow any active modes and we see no evidence of them. We also do not see evidence of Mo-Si honds in the as-deposited multilayers.

We suhjected our sample to successively higher temperature anneals starting at $200{ }^{\circ} \mathrm{C}$ and eventually reaching $1000^{\circ} \mathrm{C}$. The amorphous silicon peak disappears at about $300^{\circ} \mathrm{C}$ and no other changes are seen until $1000^{\circ} \mathrm{C}$. Curve (c) of Figure 2 shows the Raman spectra after the sample's final vacuum annealing at $1000^{\circ} \mathrm{C}$, The disappearance of the Raman peak due to amorphous silicon is noteworthy since it is opposite to what is often observed with the annealing of thicker layers of room-temperature deposited amorphous silicon. This can produce a better bonded or structurally more perfect anneal-stable amorphous silicon, possessing a Raman spect:um which is more intense and shows two humps, one centered at about $480 \mathrm{~cm}^{-1}$ and the other one lower at $170 \mathrm{~cm}^{-1}$. The intensity of the peaks typically increases and the peaks narrow with annealing. ${ }^{2+}$ The fact that this same phenomenon does not occur for the metal/silicon samples indicates that annealing may produce significantly different changes in them on an atomic level than it does in pure silicon films and silicon/dielectric multilayers. The loss of signal indicates that the Raman cross section of the silicon layers has decreased. It may be that the material is becoming more defective -- perhaps because metal atoms are diffusing into the silicon.

After this $1000{ }^{\circ} \mathrm{C}$ annealing three peaks were seen: two peaks at 323 and $438 \mathrm{~cm}^{-1}$, respectively, which can be attributed to crystalline $\mathrm{MoSi}_{2}$, and one peak at $520 \mathrm{~cm}^{-1}$, which can be attributed to crystalline silicon.

We believe that the appearance of molybdenum silicide peaks means that extensive interdiffusion has occurred and that in the interdiffusion region crystallization has begun, and that the crystallites formed are thick enough to produce detectable Raman signals. The annealing process may have produced a portion of the silicon component of multilayer crystalline. There is some possibility of the $520 \mathrm{~cm}^{-1}$ peak coming from the substrate through the film. The $250 \mathrm{~nm}$ thickness of the multilayer is sufficient to block any Raman emissions from thie substrate in the as-deposited film. Interdiffusion and reaction at $1000^{\circ} \mathrm{C}$ may have made the film more transparent at the laser's $514 \mathrm{~nm}$ line, however. We have also inspected the sample's surface for cracks or pinholes that would give the laser probe access to the substrate. In addition, the ratio of the amplitude of the $520 \mathrm{~cm}^{-1}$ peak to the $\mathrm{MoSi}_{2}$ peaks does not vary as the sample's position is changed. If it were due to pinholes it would vary. The SEM pictures of as-prepared and after $1000^{\circ} \mathrm{C}$ of multilayer surfaces were shown in Figure 3. Comparing to the result of as-prepared multilayer sample, the $1000{ }^{\circ} \mathrm{C}$ annealing made higger grains appeared on the surface and no pinholes or cracks has been seen. This indicates that some crystallization does happen. At the valley parts of the surface, the effective thickness decreased which made the substrate signal detectabie. 
The SAXRD measurement results of thick multilayer sample are shown in Figure 4. Six peaks can be seen before annealing. $1000^{\circ} \mathrm{C}$ annealing makes the multilayer structure deteriorate but there is still one peak remains which means the multilayer structure has not been totally destroyed yet. The LAXRD measurement results are shown in Figure 5. Before annealing, only two broad peaks have been observed (excluding substrate crystalline silicon signals). Peak at $14.2^{\circ}$ is $\mathrm{Si}(111)$ from $\mathrm{Si}$ layers and peak at 20.3 is metal $\mathrm{Mo}(110)$ from Mo layers. After $1000^{\circ} \mathrm{C}$ annealing, the spectrum displayed multiple new lines instead of the broad Mo peak. The identifications are shown in Table I according to standard powder diffraction file. ${ }^{27}$ From the LAXRD data we can see the evidence of existing molybdenum silicides which are caused by interciffusion and interaction at multilayer interfaces.

Table I. Identifications of LAXRD data of $1000^{\circ} \mathrm{C}$ annealed Mo/Si multilayer. The first column lists the peaks detected. The following columns list the signal identifications [khl] from the possible silicides.

\begin{tabular}{||cc|c|c|c|c||}
\hline \hline Peak\# d(nm) & $\mathrm{Mo}_{3} \mathrm{Si}$ & $\mathrm{t}-\mathrm{-} \mathrm{OoSi}_{2}$ & $\mathrm{Mo}_{5} \mathrm{Si}_{3}$ & $\mathrm{~h}-\mathrm{MoSi}_{2}$ \\
\hline 1 & 0.3207 & & & 211 & \\
\hline 2 & 0.301 & & 101 & 310 & \\
\hline 3 & 0.2715 & & & & \\
\hline 4 & 0.2447 & 200 & & 002 & \\
\hline 5 & 0.2275 & & 110 & 112 & \\
\hline 6 & 0.2177 & 210 & & 202 & 111 \\
\hline 7 & 0.2107 & & & 411 & \\
\hline 8 & 0.1988 & 211 & 103112004 & 222 & 200 \\
\hline
\end{tabular}

The same Raman and SAXRD measurements have been performed on the thin multilayer samp's. The comparisons of the results between thick and thin samples provide some useful information. The Raman spectra of the thin multilayer sample (see Figure 6) shows a similar tendency of evolution as that of thick multilayer sample. The silicide signal from interface did not appear until after $1000^{\circ} \mathrm{C}$ annealing. But there are also some differetices in thin sample spectra (see Figure 7). These differences can be explained by the fact that the film is very t:in. First of all, the peak at $520 \mathrm{~cm}^{-1}$ from crystalline silicon signal was observed even before annealing. We attribute this signal to the substrate. Based on its location we presume that the film is too thin to block the substrate signal entirely. Secondly, after $1000^{\circ} \mathrm{C}$ annealing, the silicide's signal is stronger than that of the thick film because ther: is less attenuation in it. In addition to the conclusion made above, it should be noted that the silicon signal is nat as strong in the thin sample case as for the thick sample. This supports the assertion that this peak originates hoth from the substrate and crystallized Si layers in the thick, annealed multilayer sample. In the thin sample annealing has made most of the Si layer react to form silicide which then crystallized.

Figure 8 shows the SAXRD results of the thin mu!tilayer sample. As the annealing temperature increases the diffraction peak produced by the multilayer structurs decreases until it disappears. This indicates that the multilayer structure has been totally destroyed. Anneaing at the same temperature did not eliminate the multilayer structure in the thick sample. The conclusions obtained $f$ om these data agree with those obtained from the above discussions.

Several authors have reported that annealing $\mathrm{Mo} / \mathrm{Si}$ multilayers under $600{ }^{\circ} \mathrm{C}$ will transform completely into polycrystalline mixtures of $\mathrm{Mo}_{5} \mathrm{Si}_{3}$ and both the hexagonal and tetragonal phases of $\mathrm{MoSi}_{2} .{ }^{.}$We have not seen the appearance of any molybdenum silicide until after annealing at $900{ }^{\circ} \mathrm{C}$ or ahove, ${ }^{8 *}$ and only tetragonal silicide has been obtained at these temperatures. This transitica temperature is prohably affected hy the sample deposition 
environment (sputtering gas pressure etc.) and vacuum annealing. It has been reported tiat $\mathrm{Mo} / \mathrm{Si}$ systems fabricated by different methods shows different phase transition temperatures. Further annes:ing studies may be required to see the hexagonal phase by Raman.

Raman spectroscopy may prove to be a useful and new method of characterizing $\mathrm{Mo} / \mathrm{si}$ m.ultilayers. As the data acquisition speed increases dramatically (by using CCD detector instead of PMT) it can be further developed as an in-situ characterizing technique during multilayer fabrication.

\section{CONCLUSIONS}

The Raman spectroscopy technique has been first applied to study polycrystalline MoSi, powder and characterize the as-prepared and annealed $\mathrm{Mo} / \mathrm{Si}$ soft $\mathrm{x}$-ray multilayer mirrors. The two active Ruinan modes of $\mathrm{MoSi}_{2}$ located at 323 and $438 \mathrm{~cm}^{-1}$ have been observed in powder $\mathrm{MoSi}_{2}$ and in annealed $\mathrm{Mo} / \mathrm{Si}$ multilayers. The observation of the signal due to amorphous silicon in as-deposited multilayers and its loss later with relatively modest heating indicates that significant atomic reordering is occurring at relatively modest temperatures. This observation and the observation of $\mathrm{MoSi}_{2}$ in the annealed multilayer indicate that Raman spectroscopy can be a useful technique in characterizing $\mathrm{Mo} / \mathrm{Si}$ multilayers and studying their interfaces.

\section{REFERENCES}

1. T. P. Chow and A. J. Steckl, "Refractory metal silicides: Thin-film properties and processing technology," IEEE Trans. Electron Devices, Vol. ED-30, pp. 1480, 1983.

2. S. P. Murarka, Silicides for VLSI Applications, Academic Press, New York, 1983.

3. A. L. Greer and F. Spaepen, "Diffusion," in Synthetic Modulated Structures, edited by L. Chang and B. C. Giessen, pp. 419, Academic Press, New York, 1988.

4. J. Gonzalez-Hernandez, D. D. Allred, and O. V. Nguyen, "Anneal induced changes in amorphous semiconductor multilayers, " in Interfaces, Superlattices, and Thin Films, edited by J. D. Dow and I. K. Schuller, Mat. Res. Soc. Symp. Proc. Vol. 77, pp. 665, Pittsburgh, Pennsylvania, 1987.

5: N. M. Ceglio, "Revolution in X-ray optics," J. X-Ray Sci. Technol. Vol. 1, pp. 7, 1989.

6. D. D. Allred, J. Gonzalez-Hernandez, O. V. Nguyen, D. Martin, and D. Pawlik, "Raman scattering and $\mathrm{x}$-ray diffraction characterization of amorphous semiconductor multilayer interfaces," J. Mater. Res. Vol. 1, pp. 468, 1986.

7. D. D. Allred, Q. Wang, and J. Gonzalez-Hernandez, "Characterization of metal/carbon multilayers by Raman spectroscopy," Mat. Res. Soc. Symp. Proc. Vol. 160, pp. 605, 1990.

8. T. W. Barbee, Jr., S. Mrowka, and M. C. Hettrick, "Molybdenum-silicon multilayer mirrors for the extreme ultraviolet," Appl. Opt. Vol 24, pp. 883, 1985.

9. K. Holloway, K. B. Do, and R. Sinclair, "Interfacial reactions on annealing molybdenum-silicon multilayers," J. Appl. Phys. Vol. 65, pp. 474, 1989.

10. D. G. Steams, M. B. Stearns, Y. Cheng, J. H. Stith, and N. M. Ceglio, "Thermally induced structural modification of Mo-Si multilayers," J. Appl. Phys. Vol. 67, pp. 2415, 1990.

11. D. G. Stearns, R. S. Rosen, and S. P. Vernon, "Fabrication of high-reflectance Mo-Si multilayer mirrors by planar-magnetron sputtering," J. Vac. Sci. Technol. Vol. A9, pp. 2662, 1991.

12. D. D. Allred, M. Cai, Q. Wang, D. M. Hatch, and A. Reyes-Mena, "Raman spectroscopic analysis of Mo/Si Multilayers," J. X-Ray Sci. Technol. Vol. 4, 1992.

13. P. J. Codella, F. Adar, and Y. S. Liu, "Raman microprobe analysis of tuntssten silicide, "Appl. Phys. Lett. Vol. 46, pp. 1076, 1985.

14. S. Kumar, S. Dasgupta, H. E. Jackson, and J. T. Boyd, "Raman scattering from rapid thermally annealed tungsten silicide," Appl. Phys. Lett. Vol. 50, pp. 323, 1987.

15. C. Chen, M. Cao, and W. Hua, "New material for VLSI - Formation of $\mathrm{WSi}_{2}$ by rapid thermal annealing," J. Appl. Sci. Vol. 9, pp. 258, 1991.

16. M. Amiotti, E. Bellandi, A. Borghesi, A. Piaggi, G. Guizzetti, F. Navi, and G. Queirolo, "Influence of annealing temperature on structural, electrical and optical properties of $\mathrm{WSi}_{2}, "$ Appl. 
Phys. Vol. A54, pp. 181, 1992.

17. D. Sun, Z. Yu, and F. Li, "Raman spectroscopy of the silicide $\mathrm{WSi}_{2}$ formed by co-sputtered WSi,$"$ Acta Opt. Sinica, Vol. 5, pp. 310, 1985.

18. R. J. Nemanich, M. J. Thompson, W. B. Jackson, C. C. Tsai, and B. L. Stafford, "Initial reaction at the interface of $\mathrm{Pt}$ and amorphous silicon," J. Vac. Sci. Technol. Vol. B1, pp. 519, 1983.

19. R. J. Nemanich, R. T. Fulks, B. L. Stafford, and H. A. Vander Plas, "Reactions of thin-film titanium on silicon studied by Raman spectroscopy," Appl. Phys. Lett. Vol. 46, pp. 670, 1985.

20. C. M. Doland and R. J. Nemanich, "Phase formation during reactive mclybdenum-silicide formation," J. Mater. Res. Vol. 5, pp. 2854, 1990.

21. H. Jeziorowski and H. Knōzinger, "Raman spectra of cobalt molybdenum o*ide supported on silica," J. Phys. Chem. Vol. 84, pp. 1825, 1980.

22. A. N. Desikan, L. Huang, and S. T. Oyama, "Oxygen chemisorption and laser Raman spectroscopy of unsupported and silica-supported molybdenum oxide," J. Phys. Chem. Vol. 95, pp. 10050, 1991.

23. L. Rodrigo, K. Marcinkowska, A. Adnot, P. C. Roberge, S. Kaliaguine, J. M. Stencel, L. E. Makovsky, and J. R. Diehl, "Surface science, clusters, micelles, and interfaces," J. Phys. Chem. Vol. 90, pp. 2690, 1986.

24. J. E. Smith, Jr., M. H. Brodsky, B. L. Crowder, and M. I. Nathan, "Raman spectra of amorphous $\mathrm{Si}$ and related tetragonally bonded semiconductors," Phys. Rev. Lett. Vol. 15, I r. 612, 1971.

25. D. G. Stearns, R. S. Rosen, and S. P. Vernon, "High-performance multilayer mirrors for soft x-ray projection lithography," SPIE Vol. 1547, pp. 2, 1991.

26. B. L. Henke, J. Y. Uejio, H. T. Yamada, and R. E. Tackaherry, Opt. Eng. Vol. 25, pp. 937, 1986.

27. Powder Diffraction File, Joint Committee on Powder Diffraction Standards, Swarthmors, Pennsylvania, 1974.

28. D. D. Allred, M. Cai, and D. M. Hatch, to be submitted to Phys. Rev. B. 
Figure 1. Raman spectra of $\mathrm{MOSi}_{2}$ powder: (a) as-received, (b) annealed in vacuum at 1000

- $\mathrm{C}$ for $1 \mathrm{~h}$, (c) etched in $10 \mathrm{M} \mathrm{KOH}$ and dried in air, (d) annealed in air at $500^{\circ} \mathrm{C}$ for $1 \mathrm{~h}$.

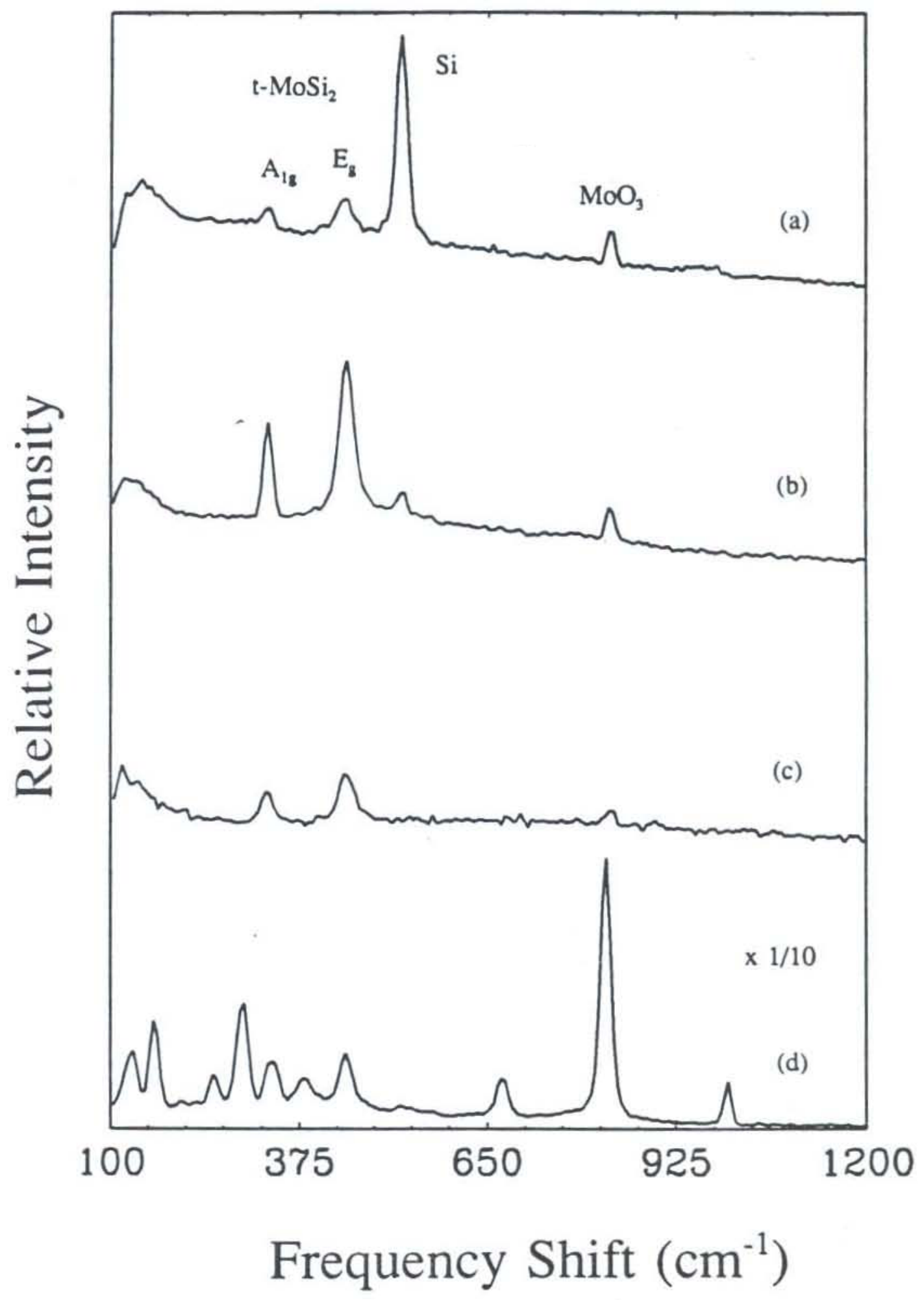


Figure 2. The Raman spectra of thick Mo/Si multilayer: (a) as-deposited, (b) annealed in vacuum at $400^{\circ} \mathrm{C}$ for $1 \mathrm{~h}$, (c) annealed in vacuum at $1000^{\circ} \mathrm{C}$ for $1 \mathrm{~h}$.

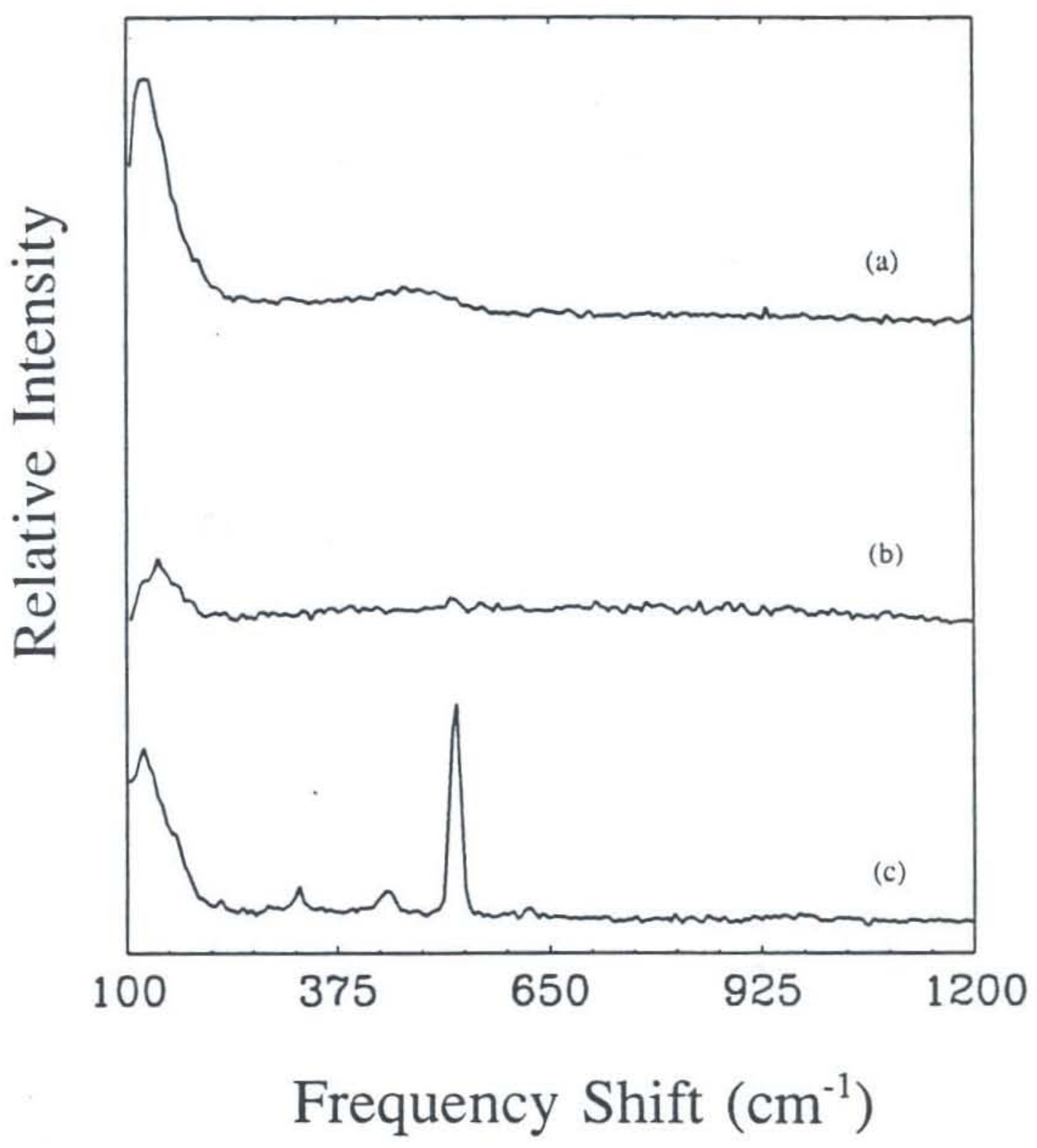


Figure 3. SEM images of thick Mo/Si multilayer sample: (a) as-deposited, (b) annealed in vacuum at $1000^{\circ} \mathrm{C}$ for $1 \mathrm{~h}$.

(a)

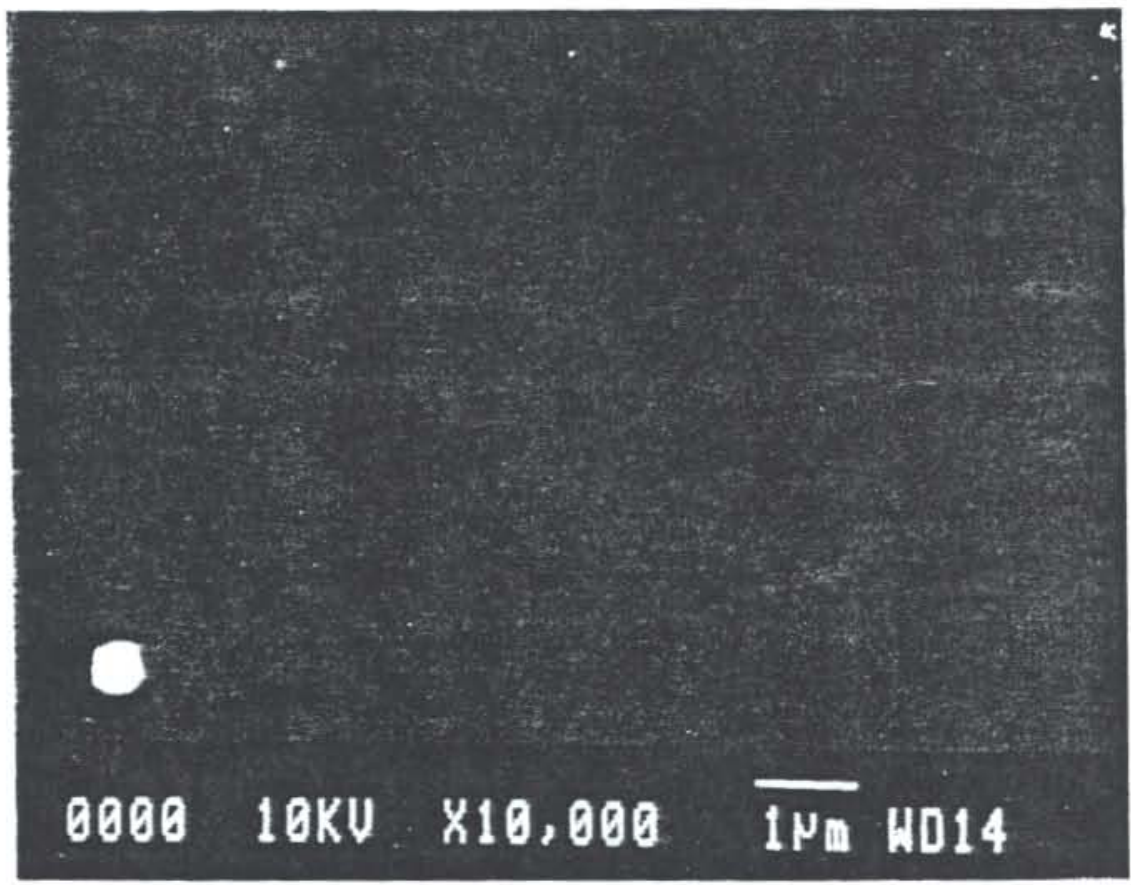

(b)

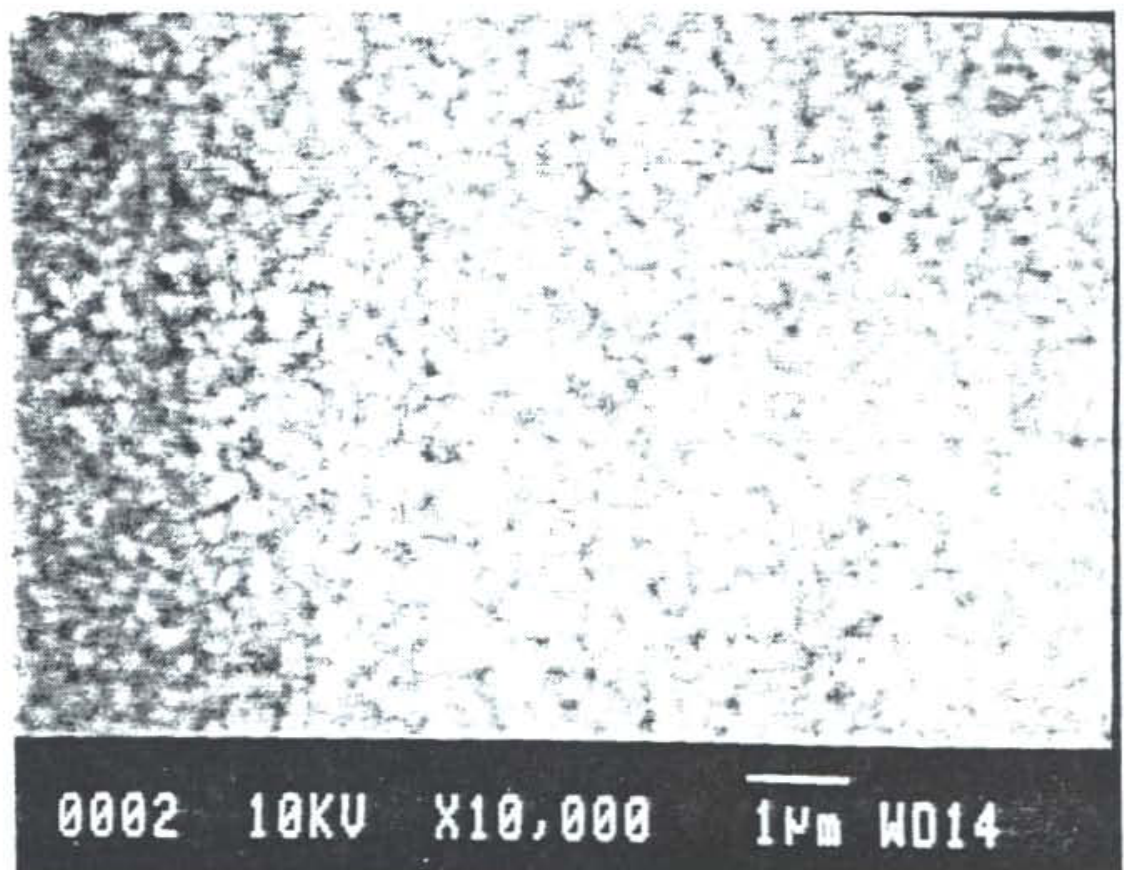


Figure 4. Small angle $x$-ray diffractions $(\lambda=0.154 \mathrm{~nm})$ measured from thick $\mathrm{Mo} / \mathrm{Si}$ multilayer: (a) as-deposited, (b) annealed in vacuum at $1000^{\circ} \mathrm{C}$ for $1 \mathrm{~h}$.
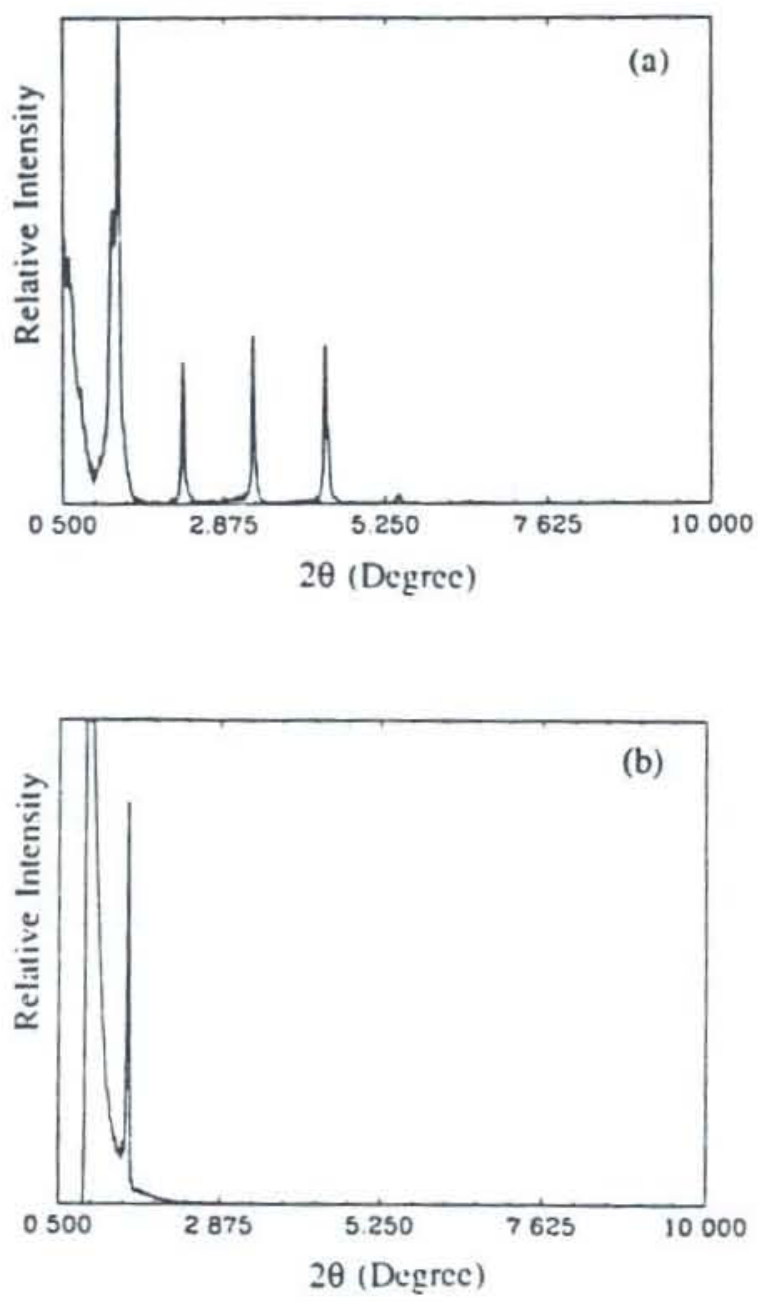
Figure 5. Large angle $\mathrm{x}$-ray diffractions measured from thick $\mathrm{Mo} / \mathrm{Si}$ multilayer and $\mathrm{MOSi}_{2}$ powder: (a) as-deposited multilayer, (b) as-received $\mathrm{MOSi}_{2}$ powder, (c) multilayer annealed in vacuum at $1000^{\circ} \mathrm{C}$ for $1 \mathrm{~h}$.
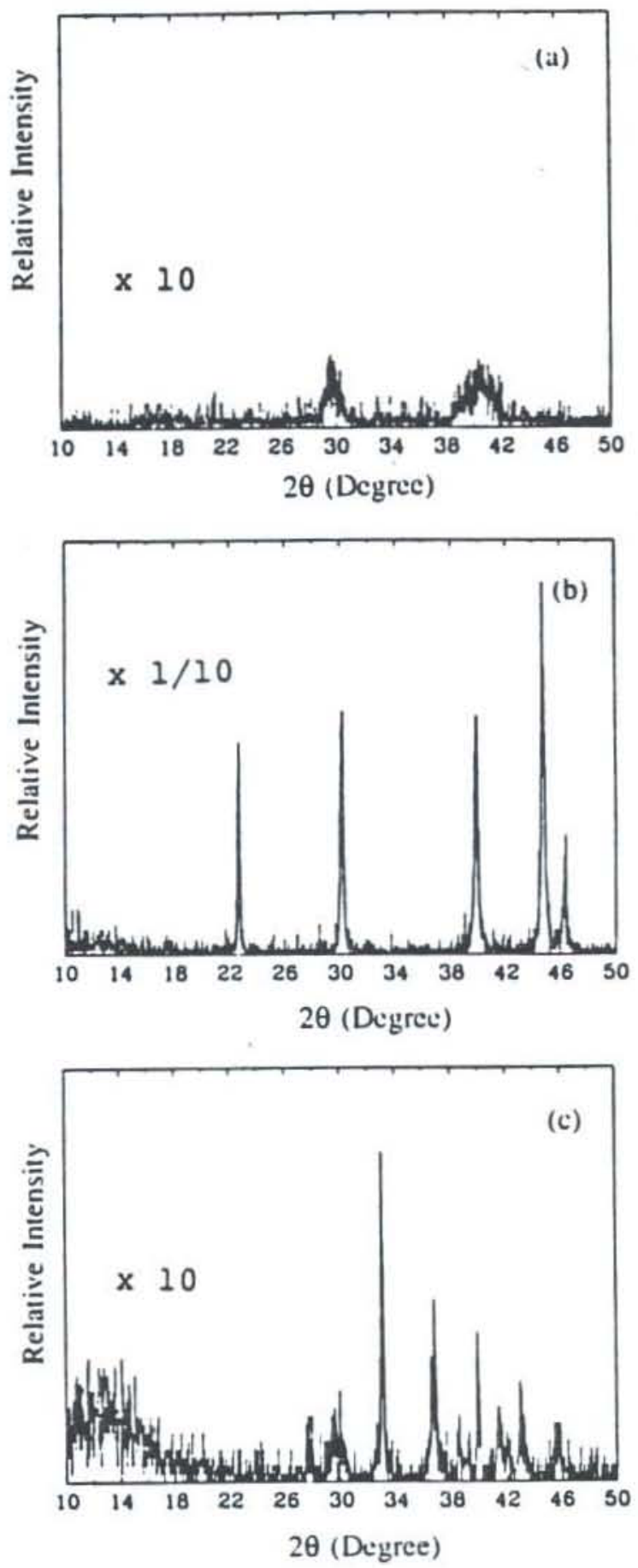
Figure 6. The Raman spectra of thin Mo/Si multilayer: (a) as-deposited, (b) annealed at 300 - C, (c) annealed at $1000^{\circ} \mathrm{C}$.

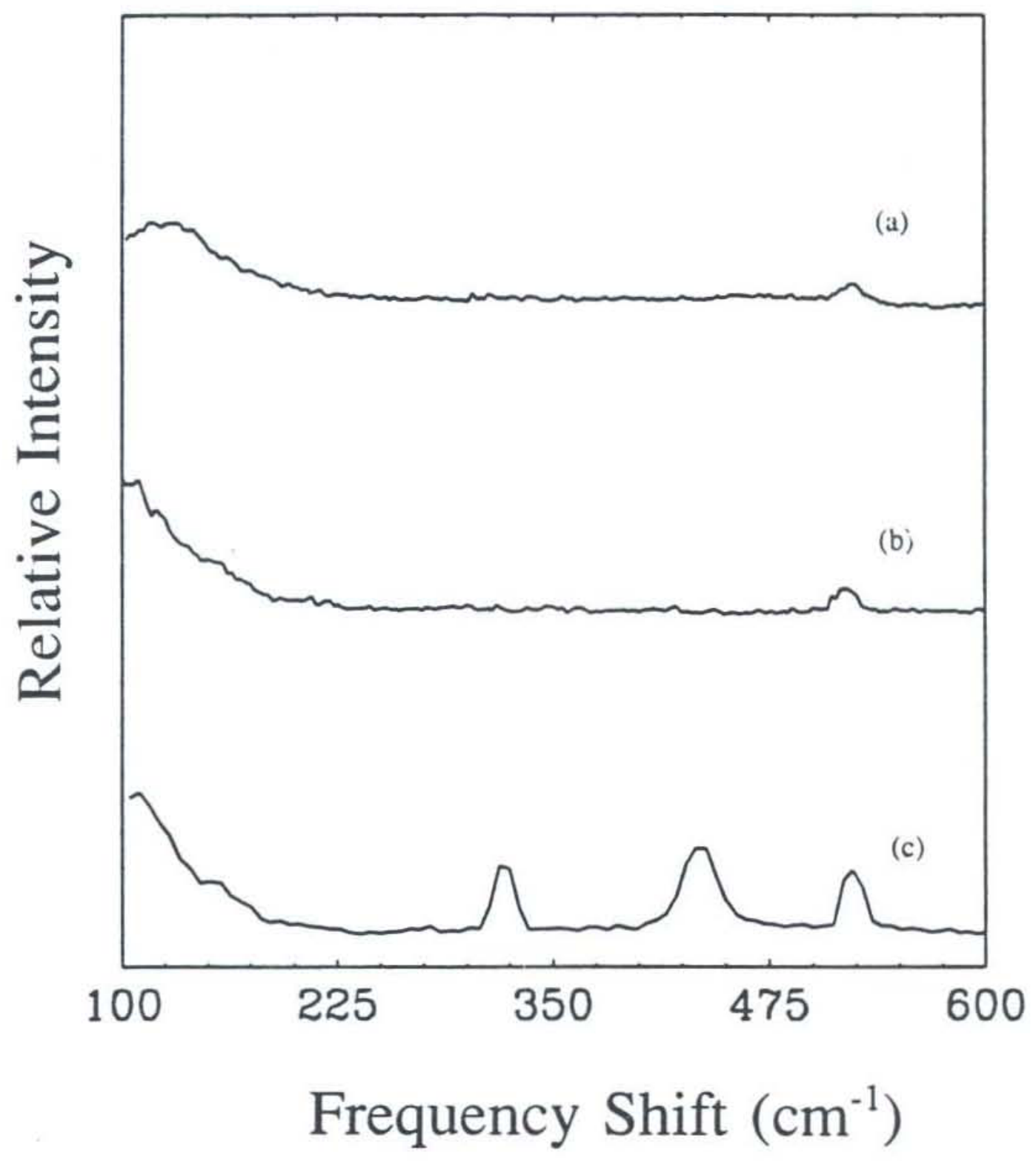


Figure 7. The Raman spectra of both thick and thin multilayer samples after $1000^{\circ} \mathrm{C}$ vacuum annealing: (a) thin sample, (b) thick sample.

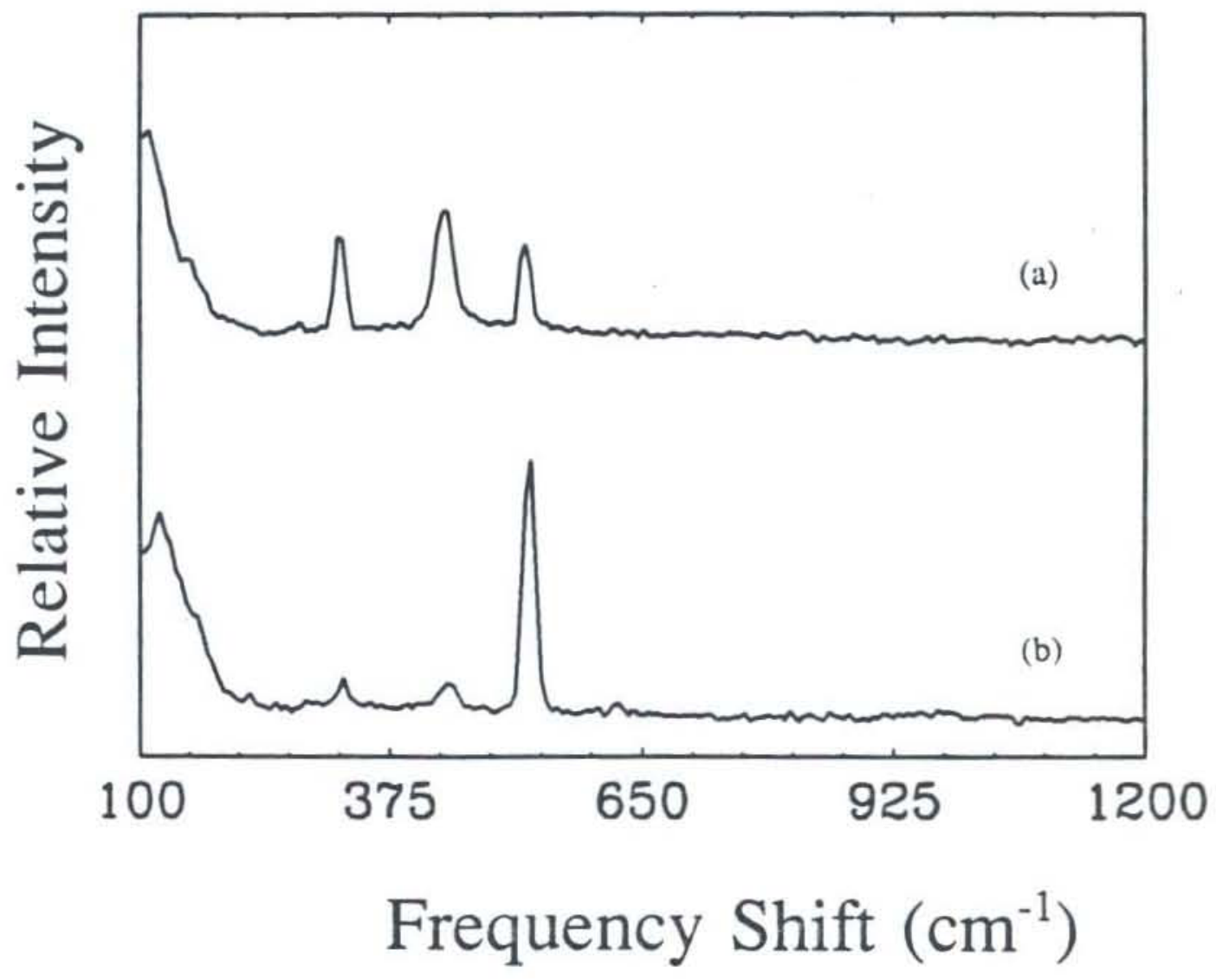


Figure 8. SAXRD measured from the thin $\mathrm{Mo/Si}$ multilayer: (a) as-deposited, (b) annealed at $300^{\circ} \mathrm{C}$ for $1 \mathrm{~h}$, (c) annealed at $600^{\circ} \mathrm{C}$ for $1 \mathrm{~h}$, (d) annealed at $900^{\circ} \mathrm{C}$ for $1 \mathrm{~h}$, (e) annealed at $1000^{\circ} \mathrm{C}$ for $1 \mathrm{~h}$.
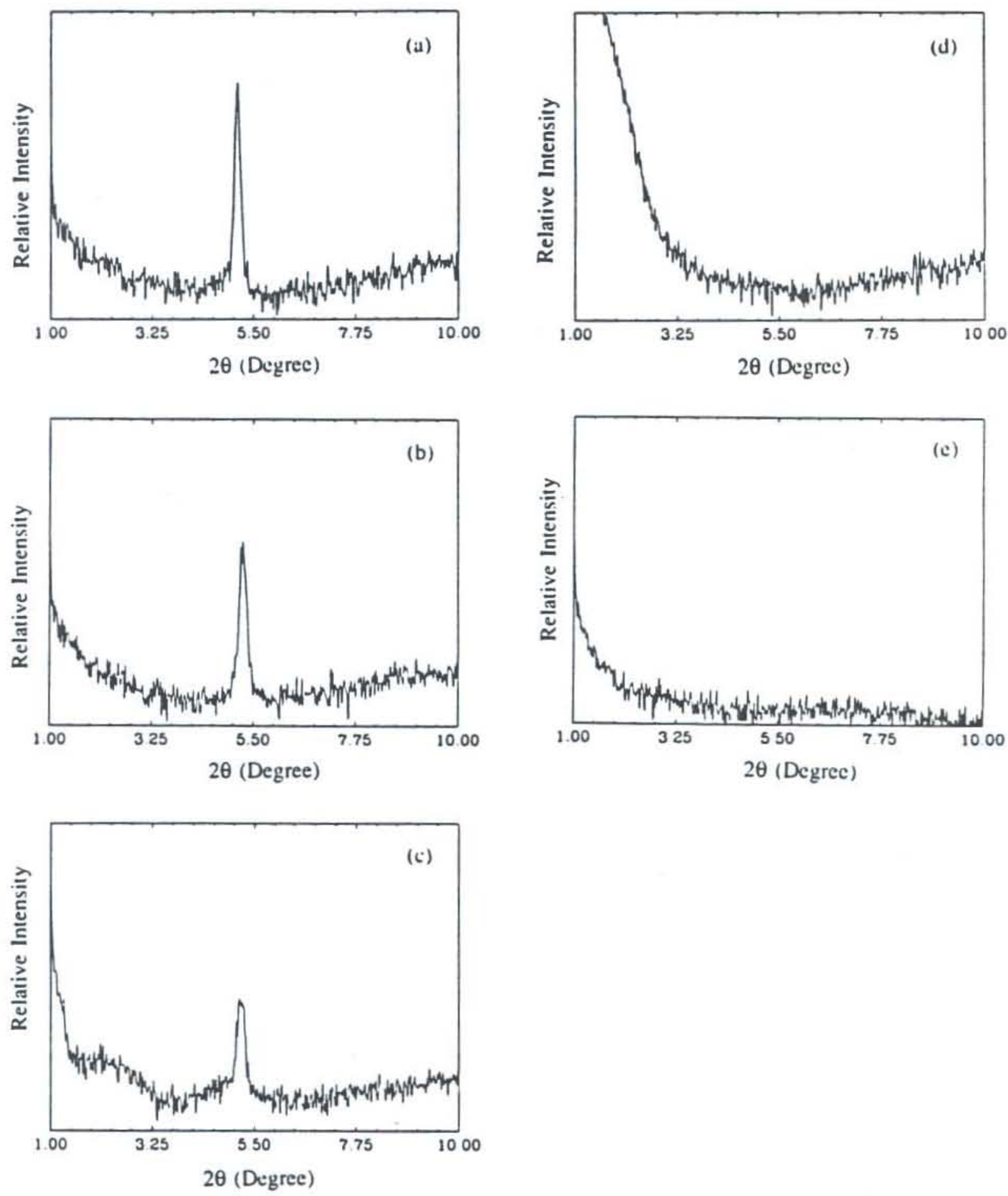


\section{DISCUSSION}

Q This assumption that these very thin $0.2 \mathrm{~nm}$ layers are going to be representative of the interface may not be correct. You have diffusion and sputtering effects that are different. Would you comment.

A We have made even thinner layers. In multilayers with low angle measurements you can actually see both layers; there are no diffraction peaks. For this one there are diffraction peaks, which indicates that even though it is very thin the multilayer structure is still maintained. The sputtering involvement will give some defect on the multilayer. The purpose of doing this sample is to try to magnify the interface effect, not to care about the reflectivity and those kind of things.

Q The $1000^{\circ} \mathrm{C}$ annealing temperature is probably not a temperature that these mirrors are ever going to see in the application, lithography or whatever. Are you going to see any effect on real mirrors or is there an integrated effect of like $100^{\circ} \mathrm{C}$ times 10 hours rather than $1000^{\circ} \mathrm{C}$ times one hour?

A People report that even at lower temperature the longer times of annealing ( some people anneal for 1000 hours) does produce some silicide from the interface. We see it for 5 hours annealing. Thus the lower temperature will produce some interface signals. 